\title{
EDIÇÃO DO CADERNO FOTOCOPIADO 1, DE EULÁLIO MOTTA
}

\author{
Ananda Paiva Santos 1 ; Patrício Nunes Barreiros ${ }^{2}$ \\ 1. Bolsista FAPESB, Graduando em Letras Vernáculas, Universidade Estadual de Feira de Santana, e-mail: \\ anandapsantos@gmail.com \\ 2. Orientador, Departamento de Letras e Artes, Universidade Estadual de Feira de Santana, e-mail: patricio@uefs.br
}

PALAVRAS-CHAVE: Caderno fotocopiado 1; Edição semidiplomática; Eulálio Motta;

\section{INTRODUÇÃO}

O escritor baiano Eulálio de Miranda Motta organizou e preservou um rico acervo de documentos pessoas que contém diversas obras literárias inéditas. Com o intuito de publicar tais obras, está sendo desenvolvido na Universidade Estadual de Feira de Santana o projeto de pesquisa Edição das obras inéditas de Eulálio Motta. Mas, para que as obras inéditas sejam publicadas, faz-se necessário editar os textos nos quais estão preservados os testemunhos de tais obras. Segundo Barreiros (2015), os cadernos do escritor são as principais fontes para se chegar a sua obra inédita. É nesse sentido que se propõe editar o Caderno fotocopiado 1, com o objetivo de identificar os testemunhos das obras inéditas do escritor e documentos paratextuais que possam elucidar tais projetos.

O Caderno Fotocopiado 1 de Eulálio Motta, trata-se já da digitalização do original que desapareceu ainda quando o acervo estava na casa onde o escritor viveu, em Mundo Novo. A fotocópia colorida encontra-se encadernada em espiral, com uma capa plástica azul transparente, contém 44 páginas, com textos manuscritos em tinta azul, preta e vermelha. Os textos estão datados de 1949 até 1955. A descrição do caderno permitiu compreender o seu conteúdo, dimensionar a quantidade de textos, suas tipologias e temáticas. O caráter crítico e ferrenho do autor diante da situação social, não só da cidade a qual pertencia, mas também da precariedade das políticas públicas do país, são pontos interessantes que os textos do Caderno fotocopiado 1 trouxeram à luz no processo da edição. Dado esses avanços no entendimento da memória sobre o olhar de um autor ímpar para a sua época, atribui - se inquestionáveis avanços nos campos linguísticos e históricos do país.

\section{MATERIAL E MÉTODOS OU METODOLOGIA}

Para facilitar o manuseio do documento foi feita a digitalização de todo o caderno e organizado um arquivo digital que corresponde a uma edição facsimiliar. O objetivo foi criar condições para elaborar uma edição face a face, na qual visualiza-se o fac-símile à esquerda e a transcrição do texto à direita (Cf. Figura 1). Os textos do caderno contêm rasuras, emendas, borrões e diversas outras características de um texto em processo de escrita. Isso exigiu uma abordagem metodológica que conciliasse os conhecimentos da Crítica Textual Moderna e da Crítica Genética.

A partir do arquivo digital procedeu-se a transcrição do texto utilizando os critérios e princípios adotados pelo grupo de edição das obras inéditas de Eulálio Motta:

a) As linhas são numeradas de 5 em 5 à margem esquerda; 
b) Os textos são transcritos em fonte Times New Roman padrão Word; de tamanho 11, justificados à margem esquerda;

c) Transcreve-se o título como se encontra no original;

d) A rubrica do autor indica-se entre colchetes;

e) São mantidas as interpolações, os lapsos do autor, a grafia, a acentuação, a pontuação e registraram-se todas as correções, emendas, rasuras e acréscimos, através da utilização de símbolos.

f) A primeira edição corresponde a uma transcrição linearizada acomodando as rasuras, substituições, correções e acréscimos na seqüência lógica do texto (não obedecendo a topografia do original);

g) Quando ocorrer a alternância da cor da tinta, deve-se indicar em nota.

Quanto aos símbolos, foram utilizados:

\{ \} seguimento riscado

$\{\dagger\}$ seguimento ilegível

$\{\dagger\} / \backslash$ segmento ilegível substituído por outro legível na relação \{ilegível\} /legível\

\{ \} / substituição por sobreposição, na relação \{substituído\} /substituto \

\{\}$[\uparrow]$ riscado e substituído por outro na entrelinha superior

\{\}$[\downarrow]$ riscado e substituído por outro na entrelinha inferior

\{\}$[\rightarrow]$ riscado e substituído por outro na margem direita

\{\}$[\leftarrow]$ riscado e substituído por outro na margem esquerda

$[\uparrow]$ acréscimo na entrelinha superior

$[\downarrow]$ acréscimo na entrelinha inferior

$[\rightarrow]$ acréscimo na margem direita

$[\leftarrow]$ acréscimo na margem esquerda

( ) intervenção do autor

\section{RESULTADOS}

Figuram no manuscrito desse caderno, 28 cartas a políticos, autoridades locais e nacionais, 7 bilhetes de conteúdo diverso, 25 textos que falam sobre fé cristã, infância, "ser poeta", alfabetização, situação política local e nacional, comunismo e integralismo, laudos de avaliação de terreno, corrupção.

Gráfico 01: Textos do caderno

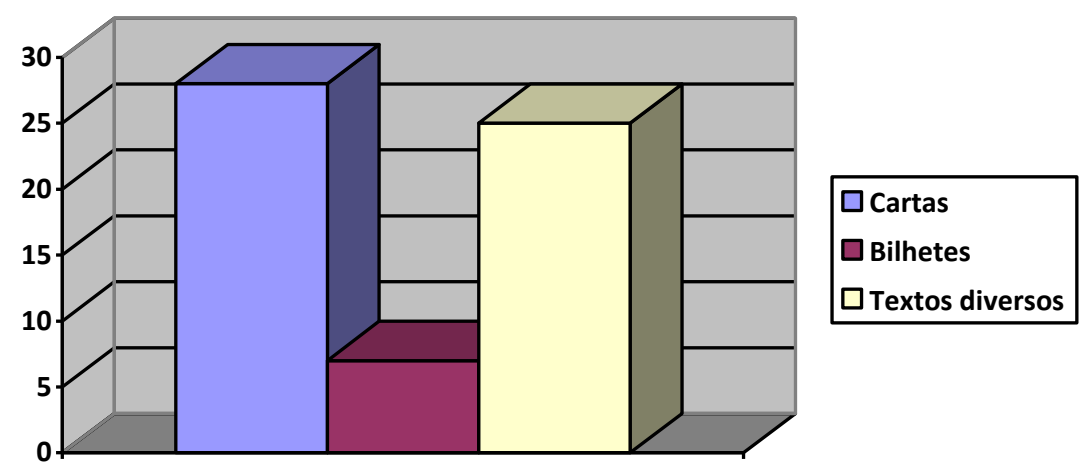


Segue o exemplo de edição de um texto em que Eulálio Motta trata do caráter religioso que permeia o campo político e revela sinais de retrocesso, pois, entende - se a partir de uma leitura contextual, para Eulálio Motta, o fato de os líderes partidários penderem ou não para uma determinada religião, não configura caráter determinante em suas ações políticas, visto que a postura do político deve ser à parte de qualquer crença ou fé.

A escrita de Eulálio Motta revela um autor crítico e pensante de uma época, um homem questionador de postura altamente relevante para a sociedade que estava inserido. Tal postura é recorrente nos demais escritos do Caderno Fotocopiado 1, objetivando os aspectos que configuram Eulálio Motta como um autor excepcional.

Figura 1: Exemplo de edição

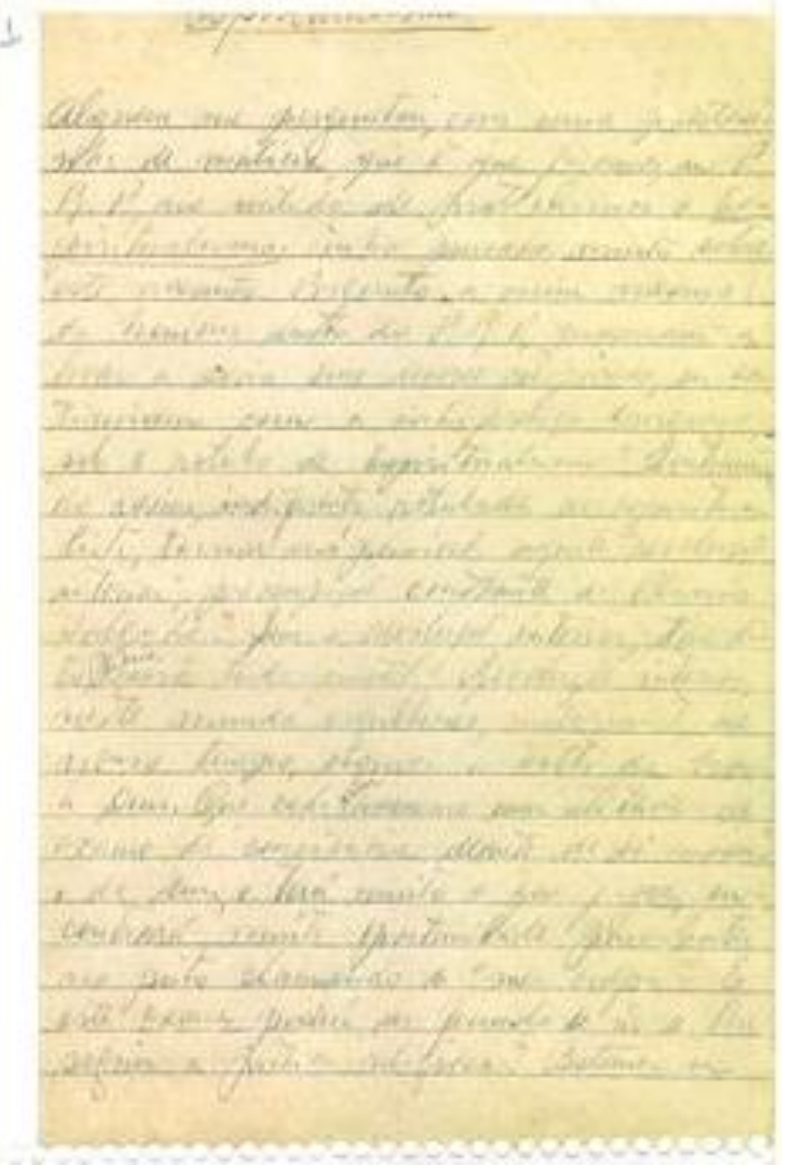

$\{\dagger\}$

Alguem me perguntou, com uma $\{\uparrow\}$ nha de malicia, que é que fazemos, sr $\mathrm{P}$. R.P., no sentido de praticarmos o Espiritismo. Tenho pensado muito sobre este assunto: Pergunto a mim mesmo: os homens, dentro do P.R.P, preservam a levar a serio seus deveres religiosos, ou timiam com a indiferença burguesa sob o estudo do Espiritismo? Continuando assim, indiferentes rotulados de espiritualista, tornar-se-á possivel aquele "solução interior", preocupação constante de Plinio Salgado? Sem a revolução interior, tem dito, Plinio, $\{\dagger\}$ tudo inutil! Revolução interior, neste mundo orgulhoso, materialista, de nosso tempo, $\{\dagger\}$ a revolta do homem a Deus. Que cada um assuma uma atitude de exame de consciencia diante de si mesmo e de Deus, e terá muito a que fazer, encontrará muita pertimidade para bater no peito clamando o "meu culpa". E este escane poderá ser fecundo se não se lhe seguir a pratica religiosa? Bastemos a

\section{CONSIDERAÇÕES FINAIS}

A pesquisa possibilitou a edição de 60 textos presentes no Caderno Fotocopiado 1. Apesar das inúmeras rasuras, borrões e emendas foi possível fazer a leitura dos textos, sem muita dificuldade.

Diante dos aspectos citados, as edições do Caderno Fotocopiado 1 proporcionaram avanços no campo de pesquisa e edição dos textos de Eulálio Motta. Chegou-se, por meio da leitura e compressão dos textos encontrados, a denominadores comuns quanto à postura do autor diante de sua faceta política. Notou-se um Eulálio Motta além de sua época, preocupado com problemas socais, de olhar sensível e braço forte diante conjuntura social e 
política do Brasil dos anos 1950. Ao assimilarmos a gênesis da escrita de Eulálio Motta, trouxemos para o campo político e literário, ganhos imateriais, de conhecimento e reflexão sobre um homem e seu tempo. A digitalização do documento, embora já proviesse de uma digitalização, estava em bom estado de conservação, o que possibilitou a ampliação no computador, método importante para a visualização de detalhes da caligrafia de Eulálio Motta. Segundo Barreiros (2015), "ir ao encontro do acervo, escrutinar a documentação, organizá-la, colocar textos inéditos em circulação ou ainda pouco conhecidos, desenvolver estudos científicos a partir das fontes encontradas, tudo isso pode ser entendido como uma forma de produção da imagem do autor e de sua obra [...]". Por meio do processo de edição esse modelo de pesquisa contribui substancialmente para a conservação e acessibilidade da memória baiana e brasileira, dando visibilidade a um autor que permanecia no anonimato. Com a preservação da escrita e atenção que se dá a forma como tal memória é descortinada pelos traços do autor, guarda - se enormes tesouros linguísticos e históricos para o país.

\section{REFERÊNCIAS}

BARREIROS, Patrício Nunes. O pasquineiro da roça: A hiperedição dos panfletos de Eulálio Motta. Feira de Santana. UEFS Editora, 2015.

BARREIROS, Patrício Nunes. Sonetos de Eulálio Motta. Feira de Santana: UEFS Editora, 2012.

BORDINI, Maria da Glória. Memória literária e novas tecnologias. Cadernos do Centro de Pesquisas Literárias da PUCRS, v. 7, n. 2, jun. 2001.

SANTOS, Rosa Borges dos. Critica textual e critica de processo: Edição e estudo do texto teatral. Rio de Janeiro: Eletrônica, 2010. 18 p. Disponível em: <http://www.filologia.org.br/xiv_cnlf/tomo_1/848-865.pdf>. Acesso em: 26 jul. 2016. 